\title{
Giardia's Epithelial Cell Interaction In Vitro: Mimicking Asymptomatic Infection?
}

\author{
Martin R. Kraft, 2*, Christian Klotz ${ }^{1}$, Roland Bücker ${ }^{2}$, Jörg-Dieter Schulzke ${ }^{2}$ and \\ Toni Aebischer ${ }^{1 *}$ \\ ${ }^{1}$ Unit 16 Mycotic and Parasitic Agents and Mycobacteria, Robert Koch-Institute, Berlin, Germany, ${ }^{2}$ Institute of Clinical \\ Physiology, Charité Campus Benjamin Franklin, Berlin, Germany
}

The protozoan parasite Giardia duodenalis is responsible for more than 280 million cases of gastrointestinal complaints ("giardiasis") every year, worldwide. Infections are acquired orally, mostly via uptake of cysts in contaminated drinking water. After transformation into the trophozoite stage, parasites start to colonize the duodenum and upper jejunum where they attach to the intestinal epithelium and replicate vegetatively. Outcome of Giardia infections vary between individuals, from self-limiting to chronic, and asymptomatic to severely symptomatic infection, with unspecific gastrointestinal complaints. One proposed mechanism for pathogenesis is the breakdown of intestinal barrier function. This has been studied by analyzing trans-epithelial electric resistances (TEER) or by indicators of epithelial permeability using labeled sugar compounds in in vitro cell culture systems, mouse models or human biopsies and epidemiological studies. Here, we discuss the results obtained mainly with epithelial cell models to highlight contradictory findings. We relate published studies to our own findings that suggest a lack of barrier compromising activities of recent $G$. duodenalis isolates of assemblage $A, B$, and $E$ in a Caco-2 model system. We propose that this epithelial cell model be viewed as mimicking asymptomatic infection. This view will likely lead to a more informative use of the model if emphasis is shifted from aiming to identify Giardia virulence factors to defining non-parasite factors that arguably appear to be more decisive for disease.

Keywords: Giardia, giardiasis, TEER, barrier function, Caco-2, transwell, permeability

\section{INTRODUCTION}

Giardia duodenalis (also Giardia lamblia or Giardia intestinalis) is an ubiquitous protozoan parasite of the order diplomonadida and forms a species complex of eight different phylogenetic groups (assemblages) characterized by different host specificities. Assemblages A and B are infectious to humans and other mammals (Thompson and Monis, 2012). It is responsible for more than 280 million symptomatic cases of infection, i.e., cases of giardiasis associated with gastrointestinal malfunctions (see below), every year, worldwide. Infections are acquired by uptake of dormant cyst forms of the parasite mostly via contaminated drinking water, and highest prevalences are reported for countries with poor access to higher sanitation standards, though it is one of the most common reported parasitic infections in other countries as well. Since 2004, more attention is paid to this pathogen due to WHO's "Neglected Diseases Initiative" (Adam, 2001; Savioli et al., 2006; Ankarklev et al., 2010). Giardia sp. cysts transform into their trophozoite stage after passing the host's stomach 
and the latter forms colonize the duodenum and upper jejunum where they replicate, attach to the intestinal epithelium using their adhesive disc and feed on luminal nutrients.

\section{THE CHALLENGE: SYMPTOMATIC VS. ASYMPTOMATIC INFECTIONS}

In the context of this article, we define a symptomatic infection, i.e., giardiasis disease, as being characterized by acute gastrointestinal complaints, like diarrhea, abdominal pain, nausea, and vomiting (Adam, 2001; Ankarklev et al., 2010) and we like to distinguish it from asymptomatic infections defined by the absence of such acute symptoms. Asymptomatic infections according to this definition would include infections thatparticularly if recurring-result in malabsorption/malnutrition phenotypes or may represent pure colonization without any pathology, which was recently shown by Garzon et al. (2017) on asymptomatic children, who found no correlation between Giardia-infection and barrier dysfunction, but only of barrier dysfunction and wasting and stunting. However, infections may also trigger post-infectious syndromes such as irritable bowel disease (D'Anchino et al., 2002; Wensaas et al., 2012; Hanevik et al., 2014; Litleskare et al., 2015; Halliez et al., 2016; Nakao et al., 2017).

The reasons for these fundamental differences of the outcomes of infections remain unclear (Adam, 2001; Troeger et al., 2007; Klotz and Aebischer, 2015; Tysnes and Robertson, 2015). A mechanism that was proposed to link to acute symptoms was the breakdown of the intestinal barrier function of the epithelium, leading to increased permeability with bacterial invasion as a possible result (Buret, 2007; Ankarklev et al., 2010). This was probably inspired by the impressive in vitro phenotypes obtained with certain bacterial, gastrointestinal pathogens and their products/toxins/proteases (Malago et al., 2003; Fajdiga et al., 2006; Rees et al., 2008; Liu et al., 2012; Anderson et al., 2013; Fiorentino et al., 2013) as well as other parasitic protozoans like Entamoeba histolytica, Cryptosporidium parvum, or Blastocystis sp. (Li et al., 1994; Leroy et al., 2000; Buret et al., 2003; Betanzos et al., 2014; Wu et al., 2014). It is fair to say that this has motivated numerous studies with the implicit goal of identifying a similar functional correlate of acutely symptomatic giardiasis in in vitro models. Here, we review in vitro investigations that aimed at finding such a robust correlate for acute clinical symptoms and conclude that, frustratingly, this goal was largely missed. We hypothesize that this is because these models reproduce the prevailing inconspicuous course of G. duodenalis infection, rather than one that is associated with acute symptoms. We propose, as others did (Bartelt and Sartor, 2015), that nonparasite factors in combination with $G$. duodenalis infection are most likely causing acute symptoms and adapting in vitro models to search for such factors should be attempted. We also propose that a number of epithelial functions that may give insight into non-acute but probably more relevant symptoms linked to malabsorption/malnutrition phenotypes have not yet been investigated in vitro but should become a focus of future work.
Two studies can serve to illustrate the dilemma that we face when trying to define pathological correlates of Giardia infection at the histological/cellular level. One study performed by Oberhuber et al. (1997) analyzed 567 Giardia-positive cases identified in a retrospective study of gastrointestinal biopsy samples collected consecutively over an eight-year period in the frame of a gastrointestinal pathology service in Germany. This number of Giardia positive cases represented $\sim 0.3 \%$ of all samples analyzed in that period. Reasons for soliciting histopathological analyses were described as follows: "most of the patients experienced unspecific gastrointestinal complaints that prompted an upper endoscopy" (Oberhuber et al., 1997). The authors conclude that "the histology of the small-bowel mucosa is inconspicuous in most subjects with giardiasis." It is reasonable to assume that such a consecutive study on biopsies sampled a random cross-sectional collection of mostly adult patients and therefore, it is justified to conclude that most Giardiainfections do not lead to acute symptoms. In contrast, a study focusing on acutely symptomatic cases reported epithelial barrier dysfunction, altered tight junction composition, and increased signs of apoptosis (Troeger et al., 2007).

\section{Epidemiological Findings on Epithelial Dysfunction}

There have been several epidemiological studies investigating functional correlates of disease such as gut permeability in different patient collectives suffering from G. duodenalis infection. Very recently Rogawski et al. (2017) and Kosek (2017), through a multisite birth-cohort study, showed that persisting infection within the first 6 months of life was correlated with reduced weight and height for age $\mathrm{Z}$ scores at 2 years of age. However, this was not dependent on diarrhea, i.e., independent of acutely symptomatic infection. More likely, stunting was the result of changes to gut permeability, assessed by Lactulose (L) and mannitol (M) excretion assays according to which permeability was positively correlated with parasite detection, which agrees with some earlier findings (Dagci et al., 2002; Goto et al., 2002) but contradicts others (Serrander et al., 1984; Campbell et al., 2004; Goto et al., 2009). Even studies using the same method vary in their results. For example, Goto et al. (2002) assessed in a cross-sectional study intestinal parasite infection and permeability of 210 Nepali children aged 0-60 months who were living in poor conditions. Fourteen percent of 173 were acutely infected with Giardia. L:M ratios suggested increased permeability in Giardia-infected $(0.43 ; n=8)$ compared to uninfected children $(0.25 ; n=45 ; p=0,014)$. However, standard deviations were very high and the stepwise multiple and logistic regression analyses used is known to be prone to type I errors (Burnham and Anderson, 2004). On the other hand, in a later longitudinal study by Goto et al. (2009) the examination of 298 children from Bangladesh until their second year of age and with comparable living conditions did not find a correlation of L:M ratios and Giardia-infection. Similar results were found in Gambian children (2-15 months of age) by another longitudinal L:M study by Campbell et al. (2004). In other studies, even a negative correlation of Giardia-infection to severe diarrhea could 
be observed (Bilenko et al., 2004; Kotloff et al., 2013; Muhsen et al., 2014).

Overall, epidemiological evidence for altered permeability as a consequence of frequent $G$. duodenalis infection exists. Effects are weak and appear to be inconsistent probably because data are confounded by non-acute, asymptomatic cases included in studied patient collectives. However, the evidence is rather against $G$. duodenalis infection alone as being a clear cause of acute symptoms such as diarrhea. In view of this data, the quest is open for improved in vitro models and respective readout parameters that may link to distinct symptoms, such as changes of permeability, molecular transport, and absorption mechanisms.

\section{Investigations of Epithelial Barrier Functions in Vitro}

Thinking of giardiasis disease as being linked to different syndromes of altered gut barrier function, acute and non-acute, should allow derivation of distinct readout parameters as proxies for the diverse symptoms when interrogating in vitro cell culture models with Giardia parasites. Current readouts include probing electrophysiological properties of epithelial cell monolayers such as trans-epithelial electric resistance (TEER), assessing transport and permeability changes using tracer molecules, or inferring monolayer integrity from changes of abundance and localization of proteins that make up tight junctions (Figure 1). In addition, epithelial tissues also function as communication layers relaying signals to other organs such as the immune system, and cytoand chemokine responses were also used as readout parameters to characterize the effect of infection.

\section{TEER as a Surrogate of Acute Effects on Tissue Integrity}

The measurement of TEER as an indicator for paracellular permeability is a well-accepted method to estimate acute pathophysiological effects on cell barrier function of intestinal epithelial cells (Srinivasan et al., 2015). An important prerequisite for a robust readout is the presence of an electro-physiologically intact monolayer. TEER measurements to investigate the effect of Giardia trophozoites on epithelial function have been used by several groups in diverse setups but were implemented with possibly relevant experimental differences (Supplementary Table 1). Our own data (Figure 2) suggest that exposure of Caco-2 cells in vitro to diverse $G$. duodenalis isolates derived from samples of symptomatic patients does not affect epithelial monolayer integrity. This is in good agreement with some previous studies (Chavez et al., 1986, 1995; Tysnes and Robertson, 2015) but is in contrast to others (Teoh et al., 2000; Humen et al., 2011; MaiaBrigagao et al., 2012), who described a TEER decrease of up to $45 \%$. If one assumes, as also proposed by others (Bartelt and Sartor, 2015), that G. duodenalis infection alone is insufficient to cause acute disease and, therefore, that infections are mostly asymptomatic, then one would not expect an effect on TEER. Since several studies have reported the contrary, however, it seems justified to analyze possible reasons for the discrepancies as they may point toward the currently elusive additional factors that are postulated here and elsewhere (Bartelt and Sartor, 2015) to precipitate acute symptoms.

As listed in Supplementary Table 1, studies differ in experimental detail and it is of interest to analyze whether these could have affected the overall outcome of the respective TEER measurements. For example, one variable of the popular Caco-2 model is that several clonal Caco-2 populations exist and their response can vary according to a particular readout (Katelaris et al., 1995; Sambuy et al., 2005; Liévin-Le Moal, 2013; Srinivasan et al., 2015). Therefore, we tested the parental cellline and the clonal cell line Caco-2 bbe in a similar settingwith the same result (Supplementary Figures 1A,B). Of note, different subpopulations-also unintentionally established by ongoing passaging of those heterogeneous cells-may explain highly different basic TEER values between setups, which range from $\sim 160 \Omega \mathrm{cm}^{2}$ (Teoh et al., 2000) to $>1,200 \Omega \mathrm{cm}^{2}$ (Scott et al., 2002). In our experiments, Caco-2 (parental) had a basic TEER of $\sim 300 \Omega \mathrm{cm}^{2}$, whereas Caco-2 bbe offered initially $\sim 200 \Omega \mathrm{cm}^{2}$ (Supplementary Figure 2) but increased this value in a linear manner after 37 passages to $350 \Omega \mathrm{cm}^{2}$ at passage \#53 (Supplementary Figure 3), which is a known phenomenon (Sambuy et al., 2005; Srinivasan et al., 2015).

Parasite number is another factor that varies between studies, where MOIs of 0.5-8 have been described (Humen et al., 2011). In our experiments, we used MOIs of similar range (1 and 10; Supplementary Figure $1 \mathrm{C}$ ) as well as very high parasite doses up to MOIs of 100 (Figure 2B or Supplementary Figures 1A,B). Thus, it seems unlikely that parasite:enterocyte ratios can explain conflicting results between studies. Specific characteristics of chosen parasite isolates cannot be excluded, but several identical isolates were tested in more than one study-including our own experiments-with different outcome (Supplementary Table 1). Thus, other differences in experimental setups must be considered.

It has been discussed that trophozoites' physical attachment alone may increase TEER and therefore obscure possible barrier defects (Chavez et al., 1995; Teoh et al., 2000; Chin et al., 2002; Tysnes and Robertson, 2015). However, exposure to the potent Giardia detachment reagent formononetin, known to remove trophozoites almost instantly without affecting their viability (Fisher et al., 2013), also did not led to normal TEERs of infected conditions (Supplementary Figure 4A). Though, formononetintreatment right after infection seem to reduce its magnitude (Supplementary Figure 4B), this contrasts to data by Humen et al. (2011), who noted a TEER decrease which was dependent on trophozoite attachment that could not be triggered by spent medium. However, spent medium and sonicates led to a decline in TEER in other studies (Teoh et al., 2000).

In many studies, infected monolayers were washed intensively with ice cold PBS to remove parasites and subsequently measured TEER (Supplementary Table 1). Our experiences with such washing procedures led to erroneously high TEERs and highly increased variances of measurements, an effect that required several hours of re-incubation to normalize (Supplementary Figure 5). In experiments that do not rely on washing, such as the use of sonicated lysates or trophozoite-conditioned DMEM, Caco-2 monolayers were shown to reduce their TEERs when 


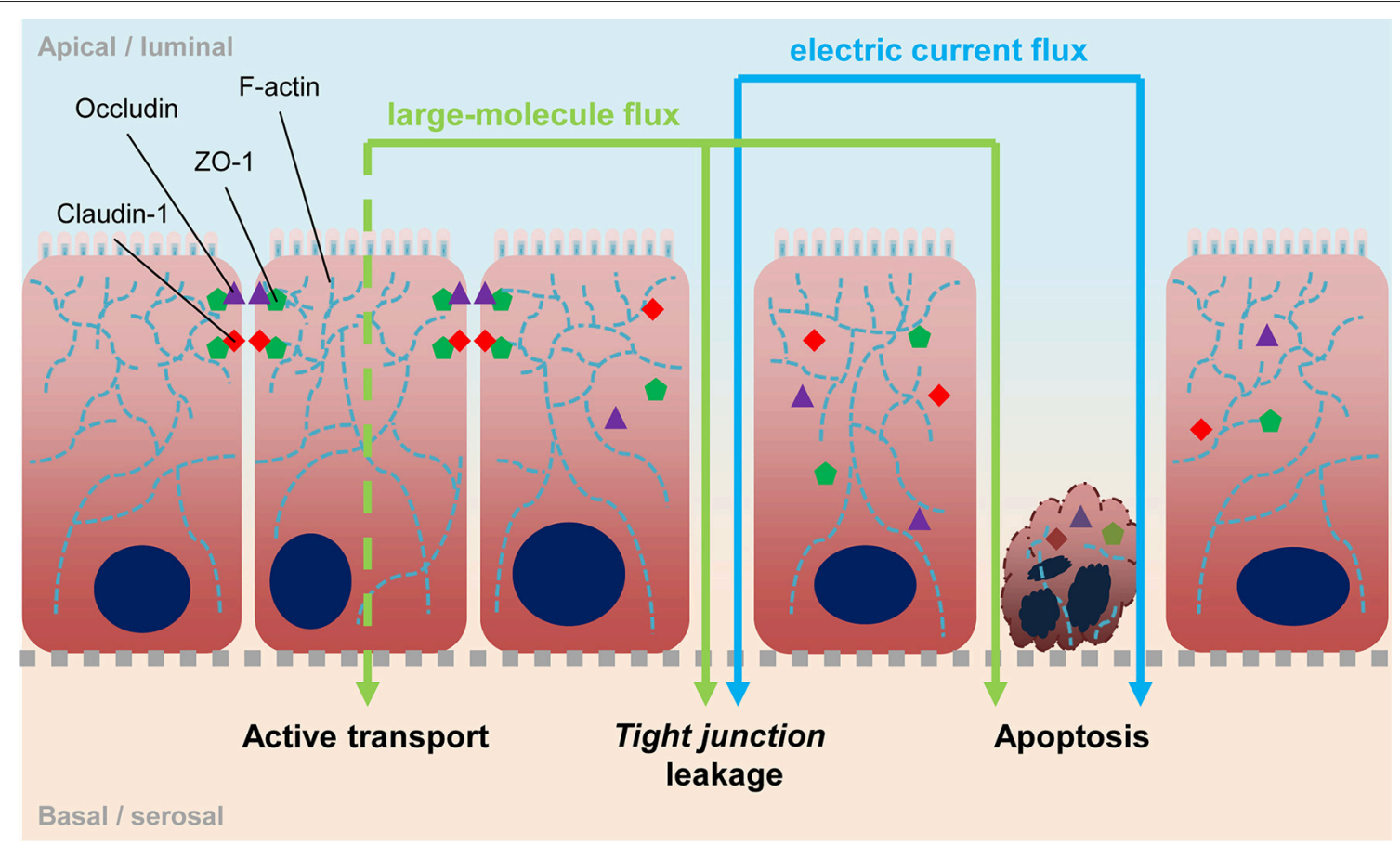

FIGURE 1 | Epithelial barrier. Scheme depicts the epithelia barrier and possible ways of its impairment. Tight junctions are located at the lateral sides in apical proximity and consist of membrane-spanning proteins like occludin and different claudins, as well as scaffold proteins like ZO-1 which connect the cytosolic ends of tight junction proteins to the actin cytoskeleton. Exchange of those proteins, leading to different tight junction compositions, affect specific permeability. Degradation of tight junctions is followed by an increase of unspecific permeability. Loss of cellular contacts lead to apoptosis and vice versa, apoptosis induces tight junction degradation. With measuring TEER, open breaches in the epithelium can be detected directly. The use of labeled molecules can also detect such leaks, however molecules can also be actively transported transcellularly e.g., via pinocytosis.

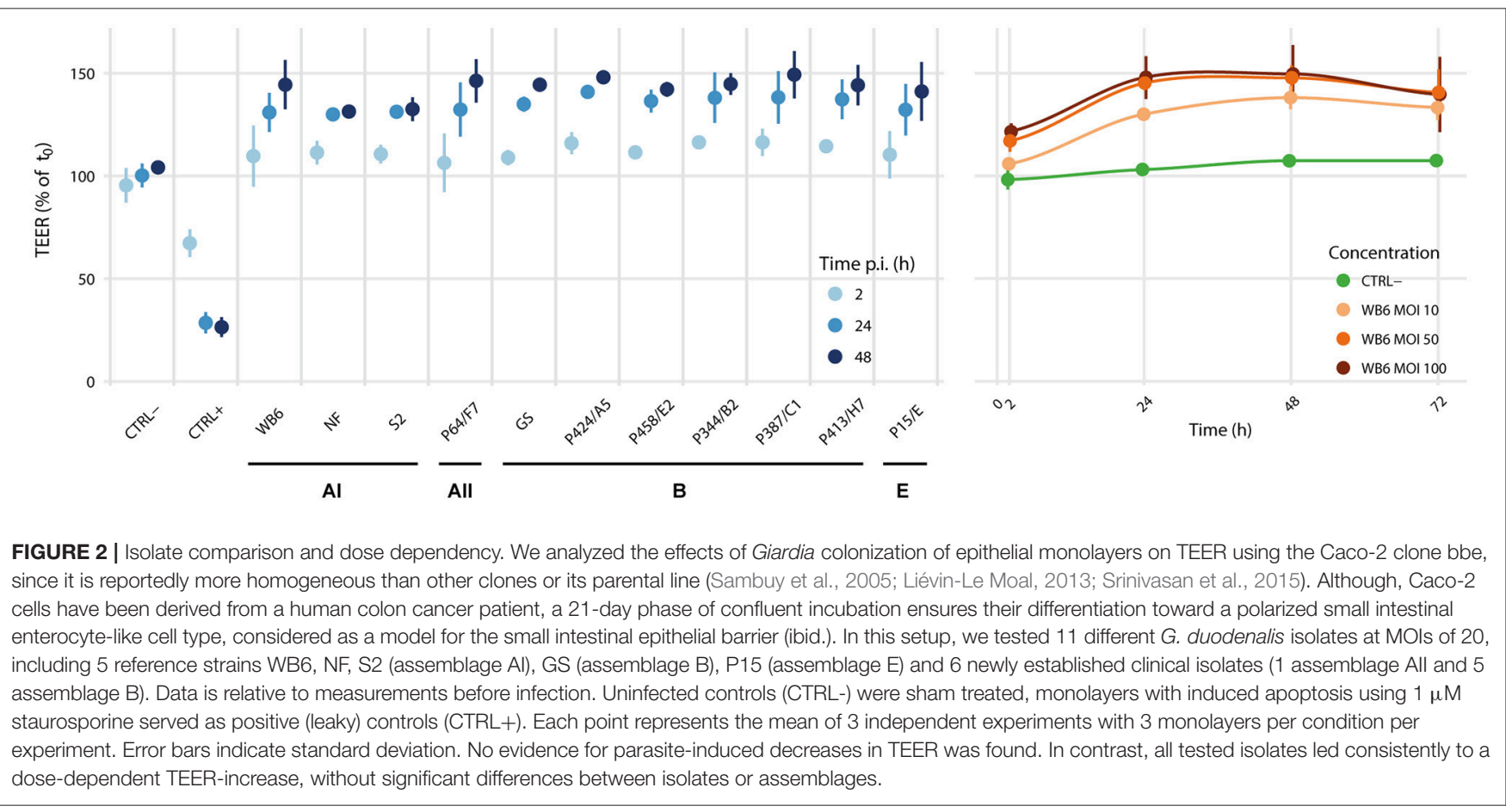


exposed to, for example, NF or S2 lysates already after $24 \mathrm{~h}$ (Teoh et al., 2000). By destroying compartmentalization, lysates may lead to release of factors such as proteases or other enzymes that affect epithelial cell function (Buret, 2007; Cotton et al., 2011, 2014; Bhargava et al., 2015). However, in our hands WB6 lysates and heat-inactivated trophozoites, both corresponding to a MOI of 20, did not influence Caco-2 monolayers' TEER (Supplementary Figure 6A), while filtered apical supernatants from a WB6-MOI-100-72-h condition weakly recapitulated the TEER increase noted in experiments with intact parasites (Supplementary Figure 6B), indicating that products of vital Giardia trophozoites, such as products of secreted microvesicles (Evans-Osses et al., 2017) or stressed Caco-2 cells, may be responsible for the observed TEER increase.

Another variation in experimental design is the time of culture and differentiation before infection (Supplementary Table 1). Since monolayers change TEER properties over time of cultivation (Supplementary Figure 2) and less differentiated cells may be more sensitive to disturbing stimuli, findings can be confounded which can explain the disparate results in seemingly similar studies (Teoh et al., 2000; Humen et al., 2011; MaiaBrigagao et al., 2012, and for own data see Supplementary Figure 7).

The medium composition is another important parameter in Giardia co-culture experiments. Complete substitution of apical DMEM volume with Giardia growth-medium TYI-S-33 can lead to a steep initial TEER increase of monolayers, that can be further accentuated if monolayers are infected with WB6 trophozoites. However, the presence of TYI-S-33 will eventually lead to the collapse of infected and non-infected monolayers (Chavez et al., 1986; Supplementary Figure 8). Thus, takeover of TYI-S-33 components can clearly be a confounder.

Although, presence of $\mathrm{O}_{2}$ for a microaerophilic pathogen is of relevance, this parameter does not seem to be decisive either. When aerobic and anaerobic conditions were compared using Caco-2 with WB6 trophozoites, anaerobic conditions showed no TEER decrease within $77 \mathrm{~h}$, but indicated a higher TEER increase in both infected and uninfected Caco-2 monolayers. Prolonged incubation led to barrier failure within $139 \mathrm{~h}$ in all anaerobically cultivated Caco-2 monolayers, whereas TEER of aerobic cultivated monolayers remained stable and-for infected conditions-elevated (Supplementary Figure 9). Of note, viability of WB6 in our setups remained high with $57-75 \%$ of trophozoites still alive after $48 \mathrm{~h}$ and $32-48 \%$ after $72 \mathrm{~h}$ in unmodified culture conditions (data not shown).

The sodium-dependent glucose cotransporter (SGLT)-1 has been shown to inhibit enterocyte apoptosis in Caco-2 cells under high glucose conditions (Yu et al., 2005, 2008). Therefore, it is possible that depending on the cell culture media applied apoptotic effects of Giardia are masked by high glucose concentrations, e.g., in the often-used standard DMEM. However, such an effect is unlikely to have occurred in studies that used the parental Caco-2 since they do not express SGLT- 1 in relevant amounts (Turner et al., 1996; Yu et al., 2008). In studies that used the Caco-2 bbe line which express this transporter (Turner et al., 1996) this is difficult to rule out, but in our experiments with the Caco-2 bbe line and low glucose conditions, comparable to $\mathrm{Yu}$ et al. did not affect TEER values when compared with cultures using normal DMEM (Supplementary Figure 10).

Serum is another possible component, capable of masking apoptosis induction, since it is known to contain corresponding inhibitors (Zoellner et al., 1996). In our experiments without FBS, however, no significant differences regarding Giardiainfection were found (Supplementary Figure 7). In contrast, the magnitude of effects of staurosporine which was used as a apoptosis-inducing control on TEER was clearly affected by FBS as predicted (Zoellner et al., 1996).

Another interesting confounder may be the Giardia lamblia virus (GLV). It is described as a double-stranded RNA virus of $7 \mathrm{~kb}$ size and belongs to the family Totiviridae (Wang and Wang, 1986; Janssen et al., 2015). GLV can infect several but not all Giardia isolates (Miller et al., 1988), depending on the expression of a specific surface receptor (Sepp et al., 1994). The related Leishmania-specific endosymbiont "Leishmania RNA virus-1" (LRV1) is known to affect the severity of leishmaniasis (Ives et al., 2011). Likewise, GLV could also influence Giardia's virulence, though no correlation regarding GLV infestation of Giardia isolates to symptomatic or asymptomatic patients were found in the past (Jonckheere and Gordts, 1987). Our experimentsat least regarding TEER-also suggest no detectable differences between GLV-infected or uninfected WB6 and GS trophozoites on Caco-2 monolayers (Supplementary Figure 11).

In summary, variations in experimental design due to the lack of standardization confound the search for robust effects on TEER induced by $G$. duodenalis. The current data in particular of the Caco-2 in vitro co-culture model rather suggests that Giardia alone does not induce acute barrier-defects.

\section{Alteration in Tight Junction Composition}

Intestinal epithelial barrier function is highly dependent on cytoskeleton architecture and tight junction composition (Hidalgo et al., 1989; Troeger et al., 2007). Giardia-induced changes in the F-actin cytoskeleton were observed after incubation with sonicates (Scott et al., 2002), with living trophozoites, sonicates and spent medium (Teoh et al., 2000) or only with attached trophozoites (Humen et al., 2011). All these studies found also alterations to respective TEER values (Supplementary Table 1). Tight junction proteins, ZO-1 and claudin-1 showed in some studies altered localization, that could be prevented by various treatments, e.g., by EGF- (Buret et al., 2002) or caspase-3 inhibitor treatment (Chin et al., 2002), or MLCK-inhibitor addition (Scott et al., 2002; see summary in Supplementary Table 1). Ex vivo-analysis of epithelial tissue from symptomatic patients, showed $30 \%$ reduced claudin- 1 abundance (Troeger et al., 2007), which was not evident in any in vitro study. On a technical note, all in vitro studies which showed alterations of the tight junction complex, experiments were conducted on plastic (chamber slides) or glass (coverslips) support which alter Caco-2 monolayer morphologies (Supplementary Figure 12).

In contrast, but in agreement with the TEER measurements, no significant differences between infected or uninfected monolayers with respect to F-actin and tight junction proteins were observed on electrophysiologically tight filter-supported 
Caco-2 layers (Figures 3, 4). Occasionally, effects as described in other studies, were detectable but lacked any correlation with infection (Figure 5). Due to heterogeneity of Caco-2 monolayers leading to a mosaic of microvilli formation (Katelaris et al., 1995; Sambuy et al., 2005; Liévin-Le Moal, 2013), the reported G. duodenalis induced microvilli depletion (Chavez et al., 1986, 1995; Buret et al., 1990, 1991) that should manifest as apical cytoskeletal changes could have been missed since changes reported were not drastic.

In conclusion, integrity of the tight junction protein complex also suggests an asymptomatic interaction of Giardia alone with the Caco- 2 model. Alterations described by others may be related to growth in non-transwell systems. Of note, described disruptive effects on ZO-1 have been described as secondary to apoptosis and not directly induced by the parasite (Chin et al., 2002; Buret et al., 2003; Bojarski et al., 2004; Zehendner et al., 2011).

\section{Epithelial Barrier Dysfunction Due To Apoptosis}

Apoptosis is a tightly regulated process in the gut epithelium. For giardiasis, reported rates vary greatly between studies from no changes to controls (Chavez et al., 1986, 1995; Katelaris et al., 1995; Maia-Brigagao et al., 2012; Tysnes and Robertson, 2015, and own findings), to minor increases from 1 to $1.5 \%$ in symptomatic patients' mucosa (Troeger et al., 2007), to isolate specific effects of sonicates (Chin et al., 2002), to significant increases up to $41 \%$ with a rather low MOI of 3 after just $16 \mathrm{~h}$ using HCT-8 cells (Panaro et al., 2007) or only significant after long term co-culture (Fisher et al., 2013). HCT-8 cells were also shown to undergo increased apoptosis in mixed isolate infections (Koh et al., 2013); a finding that we could not reproduce with Caco-2 cells using NF and S2 (data not shown). Thus, effects on apoptosis also seem to be highly dependent on experimental setup and lack the robustness to allow a clear conclusion.

\section{Tissue Permeability as a Surrogate of Altered Molecular Fluxes}

Absorption and trans-epithelial transport of biomolecules are key functions of the gut epithelia (Kiela and Ghishan, 2016) and permeation assays can be used to probe these functions.

\section{Labeled Compounds as Marker for Paracellular Permeability}

A number of in vitro studies assessed paracellular permeability using fluorescein isothiocyanate (FITC)-conjugated dextran. Buret et al. (2002) noted a more than 40-fold increase of the trans-epithelial FITC-dextran flux in co-cultures with Giardia trophozoites. This effect was associated with alterations on tight junction protein distributions (Buret et al., 2002) and could be abolished when monolayers were pretreated with epidermal growth factor (EGF). Since bovine EGF can act on human cells, and since serum used in co-culture experiments provides several growth factors with overlapping effects, differences between serum batches must be considered as potential confounders. Similar results in a comparable setting were also reported using sonicates of various Giardia isolates (WB, PB, NF, and S2; all assemblage A; Chin et al., 2002) and on SCBN monolayers (Scott et al., 2002). Interestingly, large molecule permeability could be abolished using Myosin light-chain kinase (MLCK)Inhibitor ML-9 (Scott et al., 2002). The mechanism proposed implicates phosphorylation of Myosin light-chain (MLC) by MLCK activity that leads to alterations in the F-actin and ZO-1 composition and eventually to increased permeability. An ex vivo study using FITC-dextran in Giardia GS infected mice compared effects on FITC-dextran permeability on day 7 (colonization phase) and 35 (post-clearance phase) after infection and found a slight increase in permeability at both time points of $~ 30 \%$ that was correlated with cleavage of occludin and also increased endocytosis of bacteria (Chen et al., 2013). Our findings using FITC-dextran correlate with our respective TEER measurements (Supplementary Figure 13), showing no increased permeability of Giardia-infected monolayers, but of apoptosis-induced controls. Thus, like before the in vitro findings are as contradictory-also with respect to this parameter-as the in vivo studies mentioned before.

\section{Combined Assessment of Para- and Transcellular Flux}

It is known, at least for in vivo studies, that individual sugars alone are not a reliable indicator of intestinal permeability and therefore disaccharide/monosaccharide ratios should be used instead (Johnston et al., 2000). Lactulose and mannitol for example are not transported via active monosaccharide transport systems but due to their difference in size can serve as a marker for transcellular permeability through channels (mannitol) and paracellular permeability, or tight junction leakage (lactulose; Andre et al., 1988). However, L:M ratios are not used very often in vitro, but other compounds had been used instead to assess and distinguish paracellular and transcellular flux. Using horse radish peroxidase (HRP) and creatinine as transand paracellular markers, respectively, infection with both a lab adapted and a field isolate, led to increased mucosal to serosal transcellular flux. Also paracellular permeability was increased by the field isolate (R-2), which is contradictory to the observed TEER increase in the same study (Tysnes and Robertson, 2015). Another study by Hardin et al. (1997) on Giardia S2-infected Mongolian gerbils could not find increased permeability to $\left[{ }^{51} \mathrm{Cr}\right] \mathrm{EDTA}$ (permeability similar to lactulose), but macromolecular transport of BSA was induced. A study on rats also suggest Giardia's interference with active transport, but the other way around: Glucose and glycine absorption was decreased, whereas potassium which diffuses passively through the epithelium was unaffected (Anand et al., 1980). However, one should keep in mind that malabsorption could be either a result of impaired uptake due to dissipated osmotic and ion gradients originated from leaky tight junctions and apoptotic cells, or due to a reduction in the absorptive area because of villus shortening and microvilli depletion. The latter, a reduction in absorptive area, has been shown to be one of the more consistently found pathological features of Giardia (Chavez et al., 1986, 1995; Buret et al., 1990, 1991; Troeger et al., 2007) and could explain some study discrepancies.

Results with Caco-2 cells in permeability assays have to be interpreted with caution as these cells are known to actively and passively transport contents and are extensively used in 


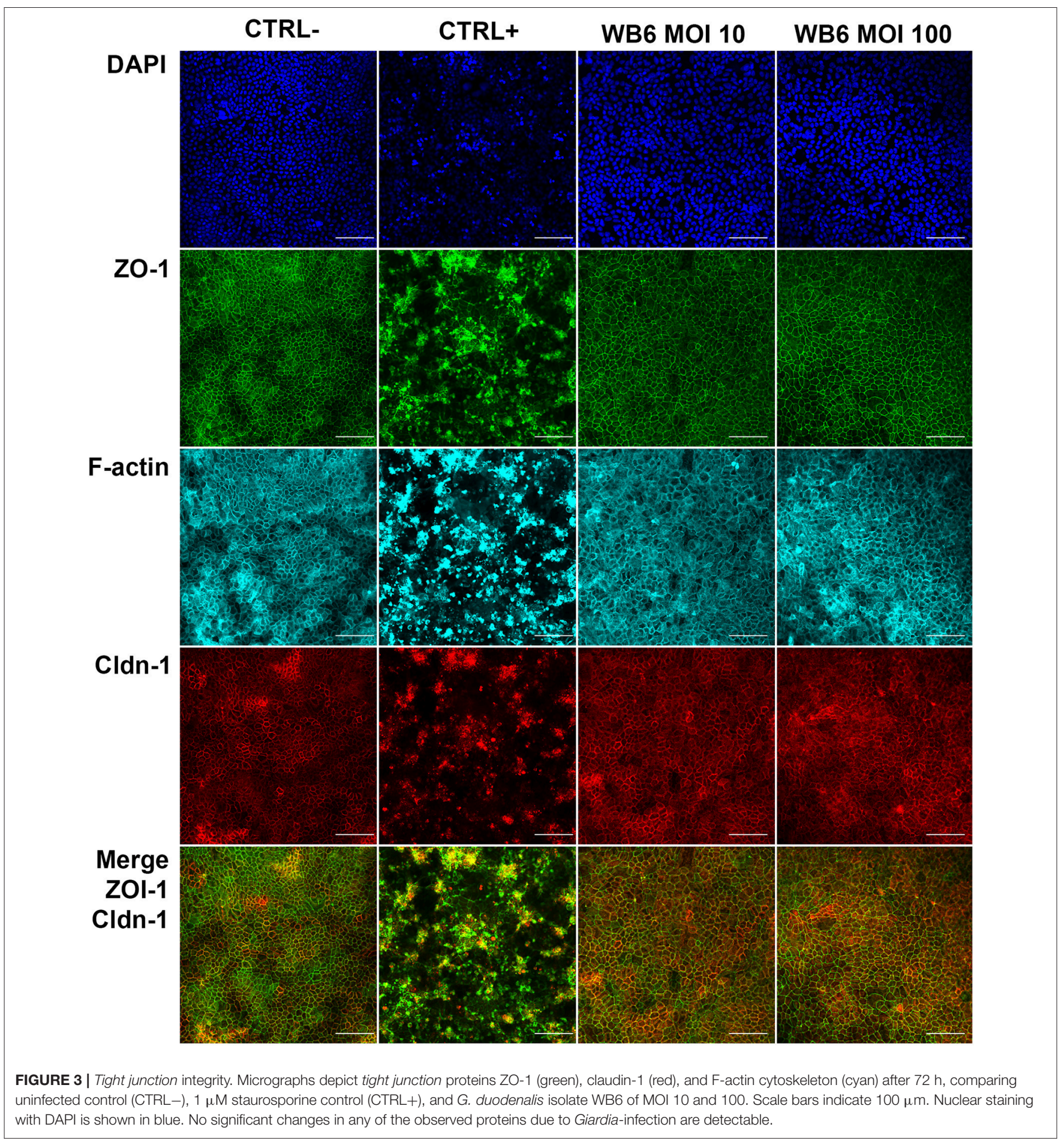

pharmaceutical drug absorption assays (Hidalgo et al., 1989; Artursson et al., 2001; Sambuy et al., 2005; Sun et al., 2008). When cultivated on plastic surfaces and not on transwellfilters, these cells tend to form large liquid-filled vacuole-like structures (Supplementary Figure 12) probably because they are not able to route those volumes through to a basally located compartment. Also, osmotically active marker substances, like sugars, can confound results by interfering with osmotic gradients. Enhanced active transport by Giardia, however, is understudied, but, should become more of a focus also because antigens or whole microbes of the intestinal lumen can be transported and be of pathological relevance. Indeed, Chen et al. (2013) found evidence for enhanced endocytosis of bacteria, rendering such a scenario possible. 


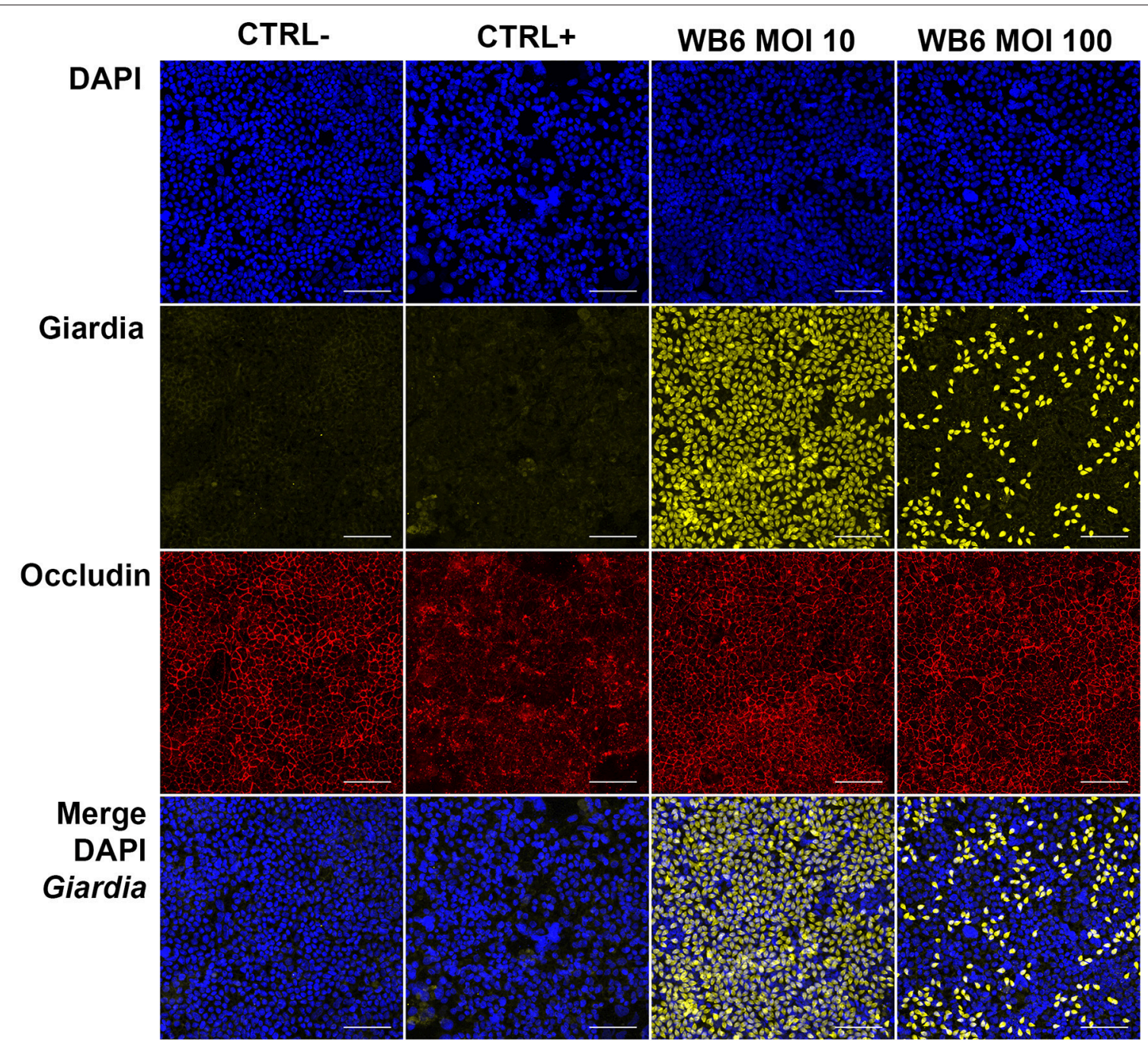

FIGURE 4 | Tight junction integrity and trophozoites. Micrographs depict tight junction protein occludin (red) and trophozoites (yellow) in Caco-2 bbe monolayer after $24 \mathrm{~h}$, comparing uninfected control (CTRL-), $1 \mu \mathrm{M}$ staurosporine control (CTRL+) and G. duodenalis isolate WB6 of MOI 10 and 100 . Scale bars indicate $100 \mu \mathrm{m}$. Nuclear staining with DAPI is shown in blue. No significant changes concerning occludin due to Giardia-infection are detectable. A MOI of 10 is sufficient to completely cover the Caco-2 monolayer. Of note, MOI 100 show artificially less trophozoites attached than MOI 10 condition, possibly due to rapid nutrient consumption followed by starvation and subsequent detachment of the trophozoites.

\section{Analysis of Chemokine/Cytokine Profiles in Giardia Epithelial Cell Co-cultures}

In order to validate the asymptomatic outcome of our Caco2 setup further, several chemokines/cytokines potentially or claimed to be upregulated during giardiasis were investigated. Most of the cytokine analyses that have been published were performed using cell monolayers grown on cell culture plastic. A seminal study used micro-array analysis of Giardia-infected Caco- 2 cells during the first $18 \mathrm{~h}$ and showed an increase in CCL20, CCL2, and CXCL1/2 mRNA abundance among others (Roxström-Lindquist et al., 2005). However, increased IL- 8 and $\mathrm{TNF} \alpha \mathrm{mRNAs}$ were not detected. Another study indicated no changes to IL-8, CCL2, GM-CSF, and TNF $\alpha$ (Jung et al., 1995). Hence, it appears that responses to Giardia infections differ from the generalized response by enterocytes of colonic origin to bacterial infections (Jung et al., 1995). This was corroborated by Fisher et al. (2013) for CCL2, GRO-isoforms (CXCL1/2), or IL-8 in the Caco-2 co-culture system. Interestingly, Caco-2 co-cultured with macrophages alone elicited GRO-isoform and IL-8 expression but this was abolished again when Giardia trophozoites were added, indicating immune-modulatory capabilities of the parasite (Fisher et al., 2013). Giardia's ability to alter immune responses has been described by others, too (Kamda and Singer, 2009; Cotton et al., 2014, 2015). Our data using the Caco-2 transwell culture system also suggest no triggering of basolateral release of CCL2/20, CXCL1/2, IL-8, TNF $\alpha$, or GM-CSF by different isolates or MOIs tested (Figure 6). Overall, our cytokine data also suggest an asymptomatic Giardia-infection. Whether this may be due to parasites' immune-modulatory features (Kamda 
A

CTRL-

CTRL+

WB6 MOI 1

WB6 MOI 10

WB6 MOI 100

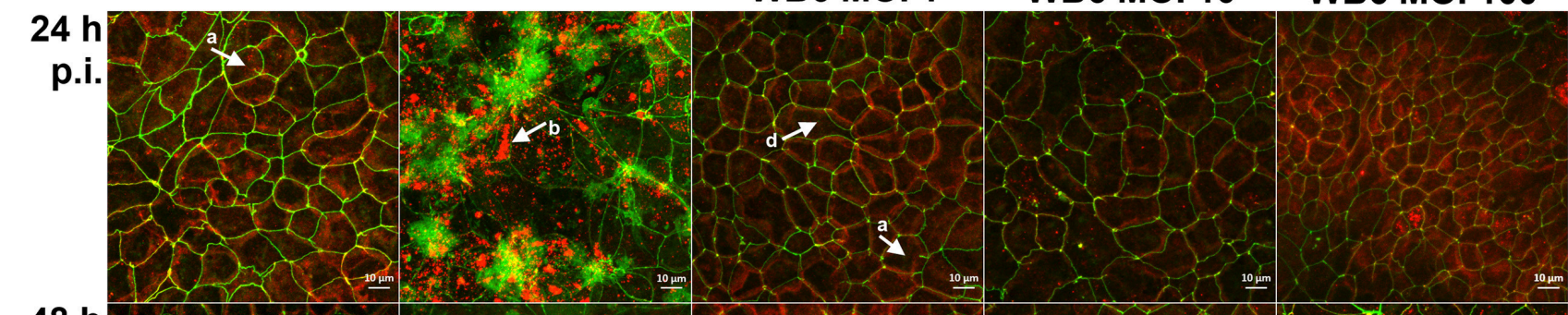

$48 \mathrm{~h}$

p.i.
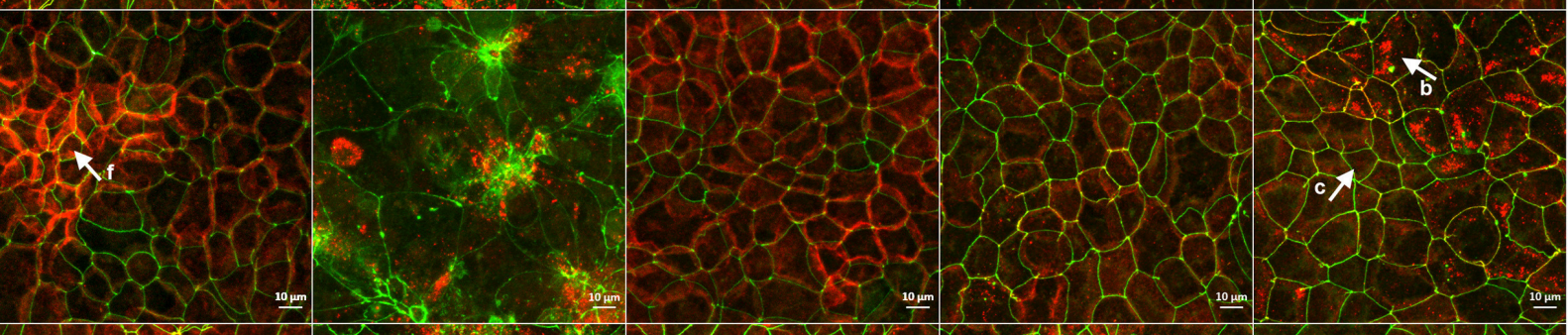

$72 \mathrm{~h}$

p.i.

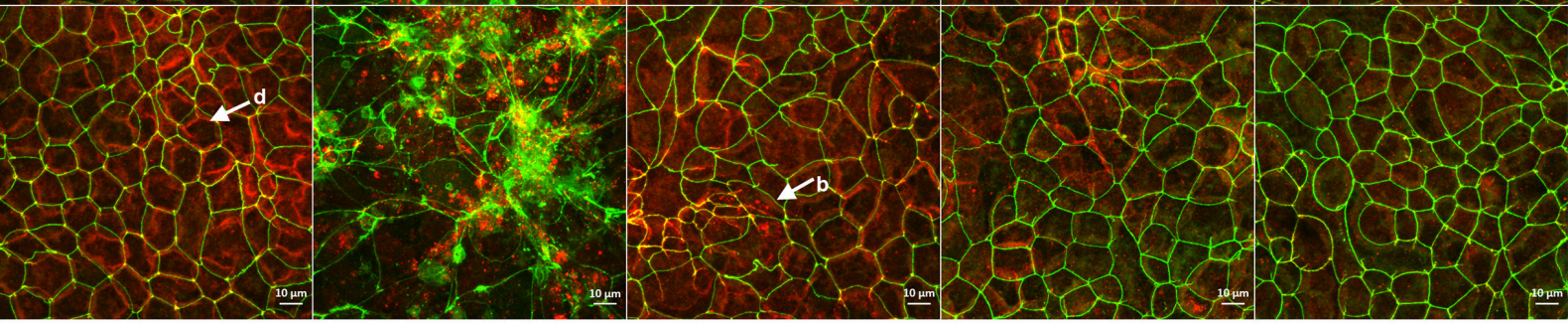

B

CTRL- 24 h p.i. $\quad$ CTRL- 72 h p.i. $\quad$ MOI 172 h p.i. $\quad$ MOI 1024 h p.i. MOI 10048 h p.i.
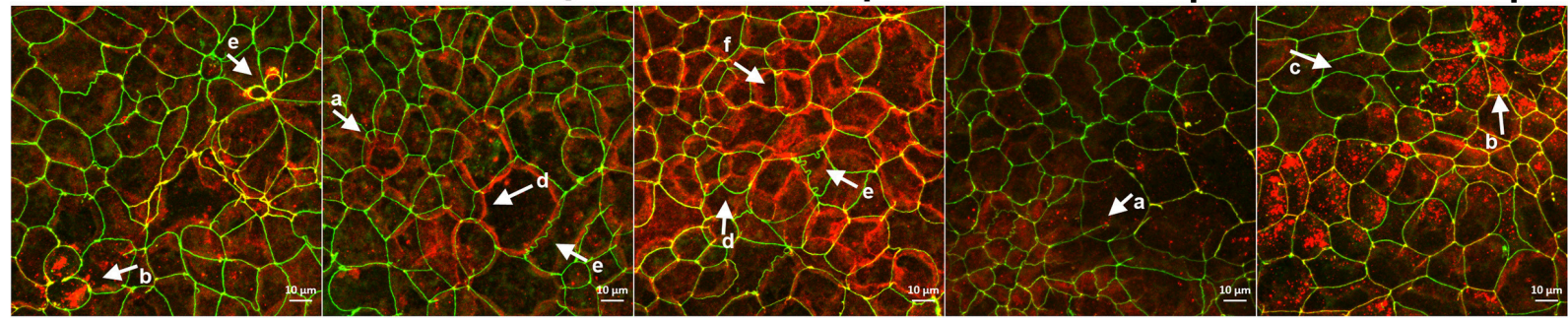

FIGURE 5 | Effects on tight junction proteins. Micrographs are derived from z-stacks, spanning whole cells, by using maximum intensity projection and depict tight junction proteins ZO-1 (green) and claudin-1 (red) in Caco-2 bbe monolayer, comparing uninfected control (CTRL-), $1 \mu \mathrm{M}$ staurosporine control (CTRL+) and G. duodenalis isolate WB6 of MOI 1, 10 and 100 after 24, 48, and $72 \mathrm{~h}$ (A). An additional selection of micrographs of same samples is shown in (B), illustrating Caco-2 peculiarities. Arrows in (A,B) indicate observed random phenotypes like ZO-1 "branching" (a), claudin-1 flocculation and delocalization (b) or its absence directly next to it (c), mismatch of ZO-1 and claudin-1 localization (d), odd cellular contacts (e), and areas of increased claudin-1 presence ( $f$ ).

and Singer, 2009; Cotton et al., 2014, 2015) requires further studies.

\section{CONCLUSION}

As mentioned in the introduction, one of the major enigmas in giardiasis is what distinguishes acutely symptomatic from asymptomatic outcomes of Giardia-infections. In this work, we reviewed and discussed current in vitro epithelial cell culture systems that we propose do reproduce asymptomatic hostparasite interaction rather than acutely symptomatic giardiasis. We propose for further development of these systems a structured approach that aims at identifying appropriate in vitro correlates for distinct clinical symptoms: The search for correlates of acute manifestations such as diarrhea could focus on readouts such as TEER, tight junction function, and ion secretion, but should focus on testing combinations of parasite and non-parasite factors. Food factors, or the lack of certain nutrients, could determine trophozoite virulence as well as bile or pancreatic secretions. Especially bile is a requirement for axenic trophozoite cultivation (Keister, 1983; Halliday et al., 1988) and it could stimulate the parasite not only to grow, but also to increase its virulence. It is also imaginable that certain host proteases could cleave Giardia proteins in a way that an inactive virulence function is activated, similar to what has been shown as a necessity for host cell 


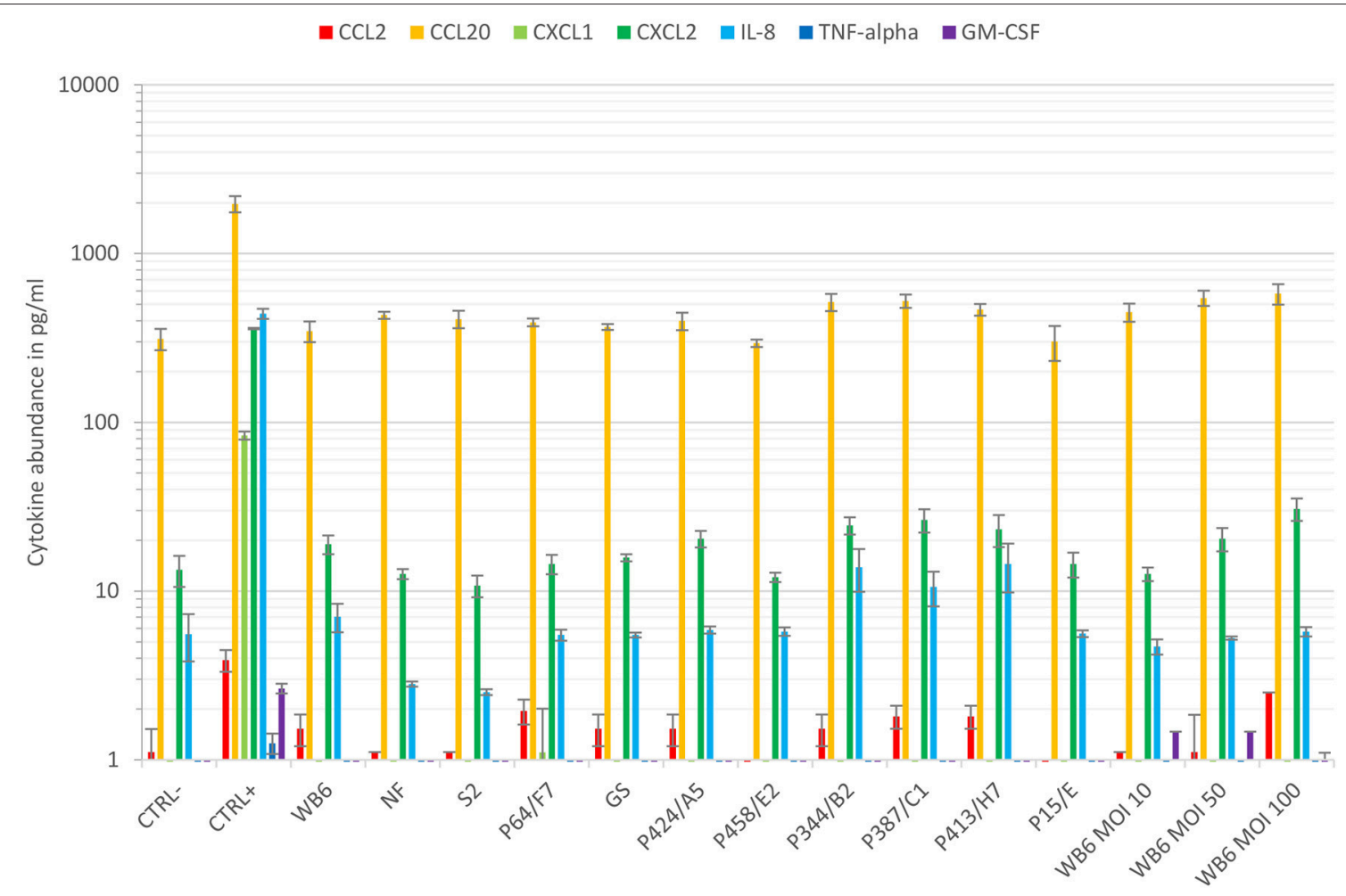

FIGURE 6 | Cytokine response. Cytokine levels of CCL2, CCL20, CXCL1, CXCL2, IL-8, TNF $\alpha$, and GM-CSF were compared using basal supernatants of the conducted $48-72 \mathrm{~h}$ TEER experiments and the Luminex ${ }^{\circledR}$ technology. Data show means and standard deviation of cytokine levels of supernatants, gathered from at least two independent TEER experiments. Except for CCL20, cytokines were barely detected in this compartment independent of infection. In contrast, monolayers insulted with staurosporine (CTRL+) increased amounts of CCL20, CXCL1/2, and IL-8, whereas CCL2, TNF $\alpha$, and GM-CSF remained below the lower quantification limit.

entry of influenza virus particles (Kido et al., 2012). Of note, Giardia specifically decreases the activity of pancreatic trypsin, but not of chymotrypsin (Seow et al., 1993), which suggests that certain proteases can be hazardous for Giardia and may disturb a finely balanced silent infection to provoke pathogenic reactions. Additionally, a host's genetic background linked to hypogammaglobulinemia, IgA deficiency or cystic fibrosis or a host's phenotype comprising reduced gastric acidity, stress, co-infections, or other concomitant diseases, could contribute to the pathogenesis (DuPont, 2013). Furthermore, since the mechanisms of trans-epithelial transport are as diverse as the respective substrates (Kiela and Ghishan, 2016) and our lack of knowledge if and how Giardia affects those transport systems, the search for correlates and explanations for more protracted effects such as stunted growth that may be linked to altered fluxes of particular biomolecules, should focus on a systematic assessment of epithelial cell functions related to those transcellular transport and absorption mechanisms. Another important factor relevant for the symptomatic outcome may be the host's microbiome, as suggested by others (Singer and Nash, 2000; Chen et al., 2013; Slapeta et al., 2015). The fact that young children after the lactation period are generally more affected by Giardia infestation than older children or adults may be an epidemiological correlate of a not-yet-settled microbiome that is more susceptible to interference by the parasite. Moreover, differences in food resources and cultural habits, resulting in distinct intestinal bacterial colonization may underlay the variances noted between studies that cover different geographic regions. Additionally, very recent publications reporting experimental findings also point toward an increasing role of the intestinal microbiota during Giardia infections (Allain et al., 2017; Barash et al, 2017; Beatty et al., 2017). Finally, since giardiasis resembles symptoms of food allergies, hypersensitivity or intolerance like coeliac disease, pathogenesis could be more related to the host's individual immune reaction (Scott et al., 2004). This might explain why Giardia-infections are less severe or even protective in developing countries, where allergic diseases are usually not as prevalent. However, due to the parasite's ability to enhance sensitization toward food antigens (Di Prisco et al., 1998), the causal relationship will be difficult to investigate. Moreover, the general in vitro methodology of Giardia-host interaction studies requires better standardization with the goal to offer robust, inter-laboratory evaluated models.

\section{AUTHOR CONTRIBUTIONS}

All authors contributed equally to design and conception of this work. MK conducted research on literature and collected experimental data. CK, RB, JS, and TA contributed to experimental design and intellectual input. $\mathrm{RB}$ and JS helped 
interpreting data and $\mathrm{MK}, \mathrm{CK}$, and $\mathrm{TA}$ contributed to the manuscript.

\section{FUNDING}

This work was financially supported by grant GRK 2046 from the German Research Foundation (DFG). The funding bodies had no role in the design of the study, collection, analysis, and interpretation of data or in writing the manuscript.

\section{ACKNOWLEDGMENTS}

We thank Ms. Wibke Krüger and Ms. Petra Gosten-Heinrich for technical assistance, as well as Prof. Staffan Svärd and Prof.
Andre Buret for intellectual input. Furthermore, we thank Prof. Andre Buret (Department of Biological Sciences, University of Calgary, Canada) for sending us NF and S2 Giardia isolates and Dr. Marco Lalle (Istituto Superiore di Sanità, Rome, Italy) for sending us "Giardia lamblia virus"-infected isolates. Finally, we thank Mr. Jonnel Jaurigue for proof-reading the manuscript.

\section{SUPPLEMENTARY MATERIAL}

The Supplementary Material for this article can be found online at: http://journal.frontiersin.org/article/10.3389/fcimb. 2017.00421/full\#supplementary-material

\section{REFERENCES}

Adam, R. D. (2001). Biology of Giardia lamblia. Clin. Microbiol. Rev. 14, 447-475. doi: 10.1128/CMR.14.3.447-475.2001

Allain, T., Amat, C. B., Motta, J.-P., Manko, A., and Buret, A. G. (2017). Interactions of Giardia sp. with the intestinal barrier: epithelium, mucus, and microbiota. Tissue Barriers 5:e1274354. doi: 10.1080/21688370.2016.1274354

Anand, B. S., Kumar, M., Chakravarti, R. N., Sehgal, A. K., and Chhuttani, P. N. (1980). Pathogenesis of malabsorption in Giardia infection: an experimental study in rats. Trans. R. Soc. Trop. Med. Hyg. 74, 565-569. doi: 10.1016/0035-9203(80)90139-X

Anderson, R. C., Young, W., Clerens, S., Cookson, A. L., McCann, M. J., Armstrong, K. M., et al. (2013). Human oral isolate Lactobacillus fermentum AGR1487 reduces intestinal barrier integrity by increasing the turnover of microtubules in Caco-2 cells. PLOS ONE 8:e78774. doi: 10.1371/journal.pone.0078774

Andre, F., Andre, C., Emery, Y., Forichon, J., Descos, L., and Minaire, Y. (1988). Assessment of the lactulose-mannitol test in Crohn's disease. Gut 29, 511-515. doi: 10.1136/gut.29.4.511

Ankarklev, J., Jerlström-Hultqvist, J., Ringqvist, E., Troell, K., and Svärd, S. G. (2010). Behind the smile: cell biology and disease mechanisms of Giardia species. Nat. Rev. Microbiol. 8, 413-422. doi: 10.1038/nrmicro2317

Artursson, P., Palm, K., and Luthman, K. (2001). Caco-2 monolayers in experimental and theoretical predictions of drug transport. Adv. Drug Deliv. Rev. 46, 27-43. doi: 10.1016/S0169-409X(96)00415-2

Barash, N. R., Maloney, J. G., Singer, S. M., and Dawson, S. C. (2017). Giardia alters commensal microbial diversity throughout the murine gut. Infect. Immun. 85:e0948-16. doi: 10.1128/IAI.00948-16

Bartelt, L. A., and Sartor, R. B. (2015). Advances in understanding Giardia: determinants and mechanisms of chronic sequelae. F1000Prime Rep. 7:62. doi: 10.12703/P7-62

Beatty, J. K., Akierman, S. V., Motta, J.-P., Muise, S., Workentine, M. L., Harrison, J. J., et al. (2017). Giardia duodenalis induces pathogenic dysbiosis of human intestinal microbiota biofilms. Int. J. Parasitol. 47, 311-326. doi: 10.1016/j.ijpara.2016.11.010

Betanzos, A., Schnoor, M., Javier-Reyna, R., García-Rivera, G., Bañuelos, C., Pais-Morales, J., et al. (2014). Analysis of the epithelial damage produced by Entamoeba histolytica infection. J. Vis. Exp. e51668. doi: 10.3791/51668

Bhargava, A., Cotton, J. A., Dixon, B. R., Gedamu, L., Yates, R. M., and Buret, A. G. (2015). Giardia duodenalis surface cysteine proteases induce cleavage of the intestinal epithelial cytoskeletal protein villin via myosin light chain kinase. PLoS ONE 10:e0136102. doi: 10.1371/journal.pone.0136102

Bilenko, N., Levy, A., Dagan, R., Deckelbaum, R. J., El-On, Y., and Fraser, D. (2004). Does co-infection with Giardia lamblia modulate the clinical characteristics of enteric infections in young children? Eur. J. Epidemiol. 19, 877-883. doi: 10.1023/B:EJEP.0000040533.75646.9c

Bojarski, C., Weiske, J., Schoneberg, T., Schroder, W., Mankertz, J., Schulzke, J.-D., et al. (2004). The specific fates of tight junction proteins in apoptotic epithelial cells. J. Cell Sci. 117, 2097-2107. doi: 10.1242/jcs.01071

Buret, A. G. (2007). Mechanisms of epithelial dysfunction in giardiasis. Gut 56, 316-317. doi: 10.1136/gut.2006.107771

Buret, A. G., Chin, A. C., and Scott, K. G. (2003). Infection of human and bovine epithelial cells with Cryptosporidium andersoni induces apoptosis and disrupts tight junctional ZO-1: effects of epidermal growth factor. Int. J. Parasitol. 33, 1363-1371. doi: 10.1016/S0020-7519(03)00138-3

Buret, A. G., Mitchell, K., Muench, D. G., and Scott, K. G. (2002). Giardia lamblia disrupts tight junctional ZO-1 and increases permeability in non-transformed human small intestinal epithelial monolayers: effects of epidermal growth factor. Parasitology 125, 11-19. doi: 10.1017/S00311820020 01853

Buret, A., Gall, D. G., and Olson, M. E. (1990). Effects of murine giardiasis on growth, intestinal morphology, and disaccharidase activity. J. Parasitol. 76, 403-409. doi: 10.2307/3282675

Buret, A., Gall, D. G., and Olson, M. E. (1991). Growth, activities of enzymes in the small intestine, and ultrastructure of microvillous border in gerbils infected with Giardia duodenalis. Parasitol. Res. 77, 109-114. doi: 10.1007/BF00935423

Burnham, K. P., and Anderson, D. R. (2004). Model Selection and Multimodel Inference: A Practical Information-Theoretic Approach, 2nd Edn. New York, NY: Springer. doi: 10.1007/b97636

Campbell, D. I., McPhail, G., Lunn, P. G., Elia, M., and Jeffries, D. J. (2004). Intestinal inflammation measured by fecal neopterin in Gambian children with enteropathy: association with growth failure, Giardia lamblia, and intestinal permeability. J. Pediatr. Gastroenterol. Nutr. 39, 153-157. doi: 10.1097/00005176-200408000-00005

Chavez, B., Gonzalez-Mariscal, L., Cedillo-Rivera, R., and Martinez-Palomo, A. (1995). Giardia lamblia: in vitro cytopathic effect of human isolates. Exp. Parasitol. 80, 133-138. doi: 10.1006/expr.1995.1015

Chavez, B., Knaippe, F., Gonzalez-Mariscal, L., and Martinez-Palomo, A. (1986). Giardia lamblia: electrophysiology and ultrastructure of cytopathology in cultured epithelial cells. Exp. Parasitol. 61, 379-389. doi: 10.1016/0014-4894(86)90194-3

Chen, T.-L., Chen, S., Wu, H.-W., Lee, T.-C., Lu, Y.-Z., Wu, L.-L., et al. (2013). Persistent gut barrier damage and commensal bacterial influx following eradication of Giardia infection in mice. Gut. Pathog. 5:26. doi: 10.1186/1757-4749-5-26

Chin, A. C., Teoh, D. A., Scott, K. G.-E., Meddings, J. B., MacNaughton, W. K., and Buret, A. G. (2002). Strain-dependent induction of enterocyte apoptosis by Giardia lamblia disrupts epithelial barrier function in a caspase-3-dependent manner. Infect. Immun. 70, 3673-3680. doi: 10.1128/IAI.70.7.3673-3680.2002

Cotton, J. A., Amat, C. B., and Buret, A. G. (2015). Disruptions of host immunity and inflammation by Giardia duodenalis: potential consequences for co-infections in the Gastro-intestinal tract. Pathogens 4, 764-792. doi: 10.3390/pathogens4040764

Cotton, J. A., Beatty, J. K., and Buret, A. G. (2011). Host parasite interactions and pathophysiology in Giardia infections. Int. J. Parasitol. 41, 925-933. doi: 10.1016/j.ijpara.2011.05.002

Cotton, J. A., Motta, J.-P., Schenck, L. P., Hirota, S. A., Beck, P. L., and Buret, A. G. (2014). Giardia duodenalis infection reduces granulocyte 
infiltration in an in vivo model of bacterial toxin-induced colitis and attenuates inflammation in human intestinal tissue. PLoS ONE 9:e109087. doi: 10.1371/journal.pone.0109087

Dagci, H., Ustun, S., Taner, M. S., Ersoz, G., Karacasu, F., and Budak, S. (2002). Protozoon infections and intestinal permeability. Acta Trop. 81, 1-5. doi: 10.1016/S0001-706X(01)00191-7

D'Anchino, M., Orlando, D., and Feudis, L., de (2002). Giardia lamblia infections become clinically evident by eliciting symptoms of irritable bowel syndrome. J. Infect. 45, 169-172. doi: 10.1053/jinf.2002.1038

Di Prisco, M. C., Hagel, I., Lynch, N. R., Jimenez, J. C., Rojas, R., Gil, M., et al. (1998). Association between giardiasis and allergy. Ann. Aller. Asthma Immunol. 81, 261-265. doi: 10.1016/S1081-1206(10)62823-2

DuPont, H. L. (2013). Giardia: both a harmless commensal and a devastating pathogen. J. Clin. Invest. 123, 2352-2354. doi: 10.1172/JCI69932

Evans-Osses, I., Mojoli, A., Monguio-Tortajada, M., Marcilla, A., Aran, V., Amorim, M., et al. (2017). Microvesicles released from Giardia intestinalis disturb host-pathogen response in vitro. Eur. J. Cell Biol. 96, 131-142. doi: 10.1016/j.ejcb.2017.01.005

Fajdiga, S., Koninkx, J. F. J. G., Tooten, P. C. J., and Marinsek-Logar, R. (2006). Interference of Salmonella enteritidis and Lactobacillus spp. with IL-8 levels and transepithelial electrical resistance of enterocyte-like Caco-2 cells. Folia Microbiol. 51, 268-272. doi: 10.1007/BF02931810

Fiorentino, M., Ding, H., Blanchard, T. G., Czinn, S. J., Sztein, M. B., and Fasano, A. (2013). Helicobacter pylori-induced disruption of monolayer permeability and proinflammatory cytokine secretion in polarized human gastric epithelial cells. Infect. Immun. 81, 876-883. doi: 10.1128/IAI.01406-12

Fisher, B. S., Estrano, C. E., and Cole, J. A. (2013). Modeling long-term host cell-Giardia lamblia interactions in an in vitro co-culture system. PLOS ONE 8:e81104. doi: 10.1371/journal.pone.0081104

Garzon, M., Pereira-da-Silva, L., Seixas, J., Papoila, A. L., Alves, M., Ferreira, F., et al. (2017). Association of enteric parasitic infections with intestinal inflammation and permeability in asymptomatic infants of Sao Tome Island. Pathog. Glob. Heal. 111, 116-127. doi: 10.1080/20477724.2017.1299831

Goto, R., Mascie-Taylor, C. G., and Lunn, P. G. (2009). Impact of intestinal permeability, inflammation status and parasitic infections on infant growth faltering in rural Bangladesh. Br. J. Nutr. 101, 1509-1516. doi: 10.1017/S0007114508083554

Goto, R., Panter-Brick, C., Northrop-Clewes, C. A., Manahdhar, R., and Tuladhar, N. R. (2002). Poor intestinal permeability in mildly stunted Nepali children: associations with weaning practices and Giardia lamblia infection. Br. J. Nutr. 88, 141-149. doi: 10.1079/BJN2002599

Halliday, C. E., Clark, C., and Farthing, M. J. (1988). Giardia-bile salt interactions in vitro and in vivo. Trans. R. Soc. Trop. Med. Hyg. 82, 428-432. doi: 10.1016/0035-9203(88)90153-8

Halliez, M. C. M., Motta, J.-P., Feener, T. D., Guerin, G., LeGoff, L., Francois, A., et al. (2016). Giardia duodenalis induces para-cellular bacterial translocation and causes post-infectious visceral hypersensitivity. Am. J. Physiol. Gastrointest. Liver Physiol. 310, G574-G585. doi: 10.1152/ajpgi.00 144.2015

Hanevik, K., Wensaas, K.-A., Rortveit, G., Eide, G. E., Morch, K., and Langeland, N. (2014). Irritable bowel syndrome and chronic fatigue 6 years after giardia infection: a controlled prospective cohort study. Clin. Infect. Dis. 59, 1394-1400. doi: 10.1093/cid/ciu629

Hardin, J. A., Buret, A. G., Olson, M. E., Kimm, M. H., and Gall, D. G. (1997). Mast cell hyperplasia and increased macromolecular uptake in an animal model of giardiasis. J. Parasitol. 83, 908-912. doi: 10.2307/3284287

Hidalgo, I. J., Raub, T. J., and Borchardt, R. T. (1989). Characterization of the human colon carcinoma cell line (Caco-2) as a model system for intestinal epithelial permeability. Gastroenterology 96, 736-749. doi: 10.1016/S0016-5085(89)80072-1

Humen, M. A., Pérez, P. F., and Liévin-Le Moal, V. (2011). Lipid raft-dependent adhesion of Giardia intestinalis trophozoites to a cultured human enterocytelike Caco-2/TC7 cell monolayer leads to cytoskeleton-dependent functional injuries. Cell. Microbiol. 13, 1683-1702. doi: 10.1111/j.1462-5822.2011.0 $1647 \mathrm{x}$

Ives, A., Ronet, C., Prevel, F., Ruzzante, G., Fuertes-Marraco, S., Schutz, F., et al. (2011). Leishmania RNA virus controls the severity of mucocutaneous leishmaniasis. Science 331, 775-778. doi: 10.1126/science.1199326
Janssen, M. E. W., Takagi, Y., Parent, K. N., Cardone, G., Nibert, M. L., and Baker T. S. (2015). Three-dimensional structure of a protozoal double-stranded RNA virus that infects the enteric pathogen Giardia lamblia. J. Virol. 89, 1182-1194. doi: 10.1128/JVI.02745-14

Johnston, S. D., Smye, M., Watson, R. G., McMillan, S. A., Trimble, E. R., and Love, A. H. (2000). Lactulose-mannitol intestinal permeability test: a useful screening test for adult coeliac disease. Ann. Clin. Biochem. 37, 512-519. doi: 10.1177/ 000456320003700413

Jonckheere, J. F., de, and Gordts, B. (1987). Occurrence and transfection of a Giardia virus. Mol. Biochem. Parasitol. 23, 85-89. doi: 10.1016/0166-6851(87)90190-3

Jung, H. C., Eckmann, L., Yang, S. K., Panja, A., Fierer, J., Morzycka-Wroblewska, E., et al. (1995). A distinct array of proinflammatory cytokines is expressed in human colon epithelial cells in response to bacterial invasion. J. Clin. Invest. 95, 55-65. doi: 10.1172/JCI117676

Kamda, J. D., and Singer, S. M. (2009). Phosphoinositide 3-kinase-dependent inhibition of dendritic cell interleukin-12 production by Giardia lamblia. Infect. Immun. 77, 1-9. doi: 10.1128/IAI.00718-08

Katelaris, P. H., Naeem, A., and Farthing, M. J. (1995). Attachment of Giardia lamblia trophozoites to a cultured human intestinal cell line. Gut 37, 512-518. doi: 10.1136/gut.37.4.512

Keister, D. B. (1983). Axenic culture of Giardia lamblia in TYI-S-33 medium supplemented with bile. Trans. R. Soc. Trop. Med. Hyg. 77, 487-488. doi: 10.1016/0035-9203(83)90120-7

Kido, H., Okumura, Y., Takahashi, E., Pan, H.-Y., Wang, S., Yao, D., et al. (2012). Role of host cellular proteases in the pathogenesis of influenza and influenza-induced multiple organ failure. Biochim. Biophys. Acta 1824, 186-194. doi: 10.1016/j.bbapap.2011.07.001

Kiela, P. R., and Ghishan, F. K. (2016). Physiology of intestinal absorption and secretion. Best Pract. Res. Clin. Gastroenterol. 30, 145-159. doi: 10.1016/j.bpg.2016.02.007

Klotz, C., and Aebischer, T. (2015). The immunological enigma of human Giardiasis. Curr. Trop. Med. Rep. 2, 119-127. doi: 10.1007/s40475-015-0050-2

Koh, W. H., Geurden, T., Paget, T., O’Handley, R., Steuart, R. F., Thompson, R. C. A., et al. (2013). Giardia duodenalis assemblage-specific induction of apoptosis and tight junction disruption in human intestinal epithelial cells: effects of mixed infections. J. Parasitol. 99, 353-358. doi: 10.1645/GE-3021.1

Kosek, M. N. (2017). Causal pathways from enteropathogens to environmental enteropathy: findings from the MAL-ED birth cohort study. EBioMedicine 18, 109-117. doi: 10.1016/j.ebiom.2017.02.024

Kotloff, K. L., Nataro, J. P., Blackwelder, W. C., Nasrin, D., Farag, T. H., Panchalingam, S., et al. (2013). Burden and aetiology of diarrhoeal disease in infants and young children in developing countries (the Global Enteric Multicenter Study, GEMS): a prospective, case-control study. Lancet 382, 209-222. doi: 10.1016/S0140-6736(13)60844-2

Leroy, A., Lauwaet, T., Bruyne, G., de, Cornelissen, M., and Mareel, M. (2000). Entamoeba histolytica disturbs the tight junction complex in human enteric T84 cell layers. FASEB J. 14, 1139-1146.

Li, E., Stenson, W. F., Kunz-Jenkins, C., Swanson, P. E., Duncan, R., and Stanley, S. L. (1994). Entamoeba histolytica interactions with polarized human intestinal Caco-2 epithelial cells. Infect. Immun. 62, 5112-5119.

Liévin-Le Moal, V. (2013). Dysfunctions at human intestinal barrier by waterborne protozoan parasites: lessons from cultured human fully differentiated colon cancer cell lines. Cell. Microbiol. 15, 860-869. doi: 10.1111/cmi.12126

Litleskare, S., Wensaas, K.-A., Eide, G. E., Hanevik, K., Kahrs, G. E., Langeland, N., et al. (2015). Perceived food intolerance and irritable bowel syndrome in a population 3 years after a giardiasis-outbreak: a historical cohort study. $B M C$ Gastroenterol. 15:164. doi: 10.1186/s12876-015-0393-0

Liu, Q., Mittal, R., Emami, C. N., Iversen, C., Ford, H. R., and Prasadarao, N. V. (2012). Human isolates of Cronobacter sakazakii bind efficiently to intestinal epithelial cells in vitro to induce monolayer permeability and apoptosis. J. Surg. Res. 176, 437-447. doi: 10.1016/j.jss.2011.10.030

Maia-Brigagao, C., Morgado-Diaz, J. A., and de Souza, W. (2012). Giardia disrupts the arrangement of tight, adherens and desmosomal junction proteins of intestinal cells. Parasitol. Int. 61, 280-287. doi: 10.1016/j.parint.2011.11.002

Malago, J. J., Koninkx, J. F. J. G., Ovelgonne, H. H., van Asten, F. J. A. M., Swennenhuis, J. F., and van Dijk, J. E. (2003). Expression levels of heat shock proteins in enterocyte-like Caco-2 cells after 
exposure to Salmonella enteritidis. Cell Stress Chaperones 8, 194-203. doi: 10.1379/1466-1268(2003)008\&lt;0194:ELOHSP\&gt;2.0.CO;2

Miller, R. L., Wang, A. L., and Wang, C. C. (1988). Identification of Giardia lamblia isolates susceptible and resistant to infection by the double-stranded RNA virus. Exp. Parasitol. 66, 118-123. doi: 10.1016/0014-4894(88)90056-2

Muhsen, K., Cohen, D., and Levine, M. M. (2014). Can Giardia lamblia infection lower the risk of acute diarrhea among preschool children? J. Trop. Pediatr. 60, 99-103. doi: 10.1093/tropej/fmt085

Nakao, J. H., Collier, S. A., and Gargano, J. W. (2017). Giardiasis and subsequent irritable bowel syndrome: a longitudinal cohort study using health insurance data. J. Infect. Dis. 215, 798-805. doi: 10.1093/infdis/jiw621

Oberhuber, G., Kastner, N., and Stolte, M. (1997). Giardiasis: a histologic analysis of 567 cases. Scand. J. Gastroenterol. 32, 48-51. doi: 10.3109/00365529709025062

Panaro, M. A., Cianciulli, A., Mitolo, V., Mitolo, C. I., Acquafredda, A., Brandonisio, O., et al. (2007). Caspase-dependent apoptosis of the HCT-8 epithelial cell line induced by the parasite Giardia intestinalis. FEMS Immunol. Med. Microbiol. 51, 302-309. doi: 10.1111/j.1574-695X.2007.00304.x

Rees, L. E. N., Cogan, T. A., Dodson, A. L., Birchall, M. A., Bailey, M., and Humphrey, T. J. (2008). Campylobacter and IFNgamma interact to cause a rapid loss of epithelial barrier integrity. Inflamm. Bowel Dis. 14, 303-309. doi: $10.1002 /$ ibd.20325

Rogawski, E. T., Bartelt, L. A., Platts-Mills, J. A., Seidman, J. C., Samie, A., Havt, A., et al. (2017). Determinants and impact of giardia infection in the first 2 years of life in the MAL-ED birth cohort. J. Pediatr. Infect. Dis. Soc. 6, 153-160. doi: 10.1093/jpids/piw082

Roxström-Lindquist, K., Ringqvist, E., Palm, D., and Svärd, S. (2005). Giardia lamblia-induced changes in gene expression in differentiated Caco-2 human intestinal epithelial cells. Infect. Immun. 73, 8204-8208. doi: 10.1128/IAI.73.12.8204-8208.2005

Sambuy, Y., Angelis, I., de, Ranaldi, G., Scarino, M. L., Stammati, A., and Zucco, F. (2005). The Caco-2 cell line as a model of the intestinal barrier: influence of cell and culture-related factors on Caco-2 cell functional characteristics. Cell Biol. Toxicol. 21, 1-26. doi: 10.1007/s10565-005-0085-6

Savioli, L., Smith, H., and Thompson, A. (2006). Giardia and Cryptosporidium join the 'Neglected diseases initiative'. Trends Parasitol. 22, 203-208. doi: 10.1016/j.pt.2006.02.015

Scott, K. G., Meddings, J. B., Kirk, Lees-Miller, S. P., and Buret, A. G. (2002). Intestinal infection with Giardia spp. reduces epithelial barrier function in a myosin light chain kinase-dependent fashion. Gastroenterology 123, 1179-1190. doi: 10.1053/gast.2002.36002

Scott, K. G.-E., Yu, L. C. H., and Buret, A. G. (2004). Role of CD8+ and CD4+ T lymphocytes in jejunal mucosal injury during murine giardiasis. Infect. Immun. 72, 3536-3542. doi: 10.1128/IAI.72.6.3536-3542.2004

Seow, F., Katelaris, P., and Ngu, M. (1993). The effect of Giardia lamblia trophozoites on trypsin, chymotrypsin and amylase in vitro. Parasitology 106, 233. doi: $10.1017 /$ S0031182000075053

Sepp, T., Wang, A. L., and Wang, C. C. (1994). Giardiavirus-resistant Giardia lamblia lacks a virus receptor on the cell membrane surface. J. Virol. 68, 1426-1431.

Serrander, R., Magnusson, K. E., and Sundqvist, T. (1984). Acute infections with Giardia lamblia and rotavirus decrease intestinal permeability to low-molecular weight polyethylene glycols (PEG 400). Scand. J. Infect. Dis. 16, 339-344. doi: 10.3109/00365548409073958

Singer, S. M., and Nash, T. E. (2000). The role of normal flora in Giardia lamblia infections in mice. J. Infect. Dis. 181, 1510-1512. doi: 10.1086/315409

Slapeta, J., Dowd, S. E., Alanazi, A. D., Westman, M. E., and Brown, G. K. (2015). Differences in the faecal microbiome of non-diarrhoeic clinically healthy dogs and cats associated with Giardia duodenalis infection: impact of hookworms and coccidia. Int. J. Parasitol. 45, 585-594. doi: 10.1016/j.ijpara.2015.04.001

Srinivasan, B., Kolli, A. R., Esch, M. B., Abaci, H. E., Shuler, M. L., and Hickman, J. J. (2015). TEER measurement techniques for in vitro barrier model systems. J. Lab. Autom. 20, 107-126. doi: 10.1177/2211068214561025
Sun, H., Chow, E. C., Liu, S., Du, Y., and Pang, K. S. (2008). The Caco-2 cell monolayer: usefulness and limitations. Expert Opin. Drug Metab. Toxicol. 4, 395-411. doi: 10.1517/17425255.4.4.395

Teoh, D. A., Kamieniecki, D., Pang, G., and Buret, A. G. (2000). Giardia lamblia rearranges F-actin and alpha-actinin in human colonic and duodenal monolayers and reduces transepithelial electrical resistance. J. Parasitol. 86, 800-806. doi: 10.1645/0022-3395(2000)086[0800:GLRFAA]2.0.CO;2

Thompson, R. A., and Monis, P. (2012). Giardia-from genome to proteome. Adv. Parasitol. 78, 57-95. doi: 10.1016/B978-0-12-394303-3. 00003-7

Troeger, H., Epple, H.-J., Schneider, T., Wahnschaffe, U., Ullrich, R., Burchard, G.-D., et al. (2007). Effect of chronic Giardia lamblia infection on epithelial transport and barrier function in human duodenum. Gut 56, 328-335. doi: 10.1136/gut.2006.100198

Turner, J. R., Lencer, W. I., Carlson, S., and Madara, J. L. (1996). Carboxyterminal vesicular stomatitis virus $\mathrm{G}$ protein-tagged intestinal $\mathrm{Na}+$-dependent glucose cotransporter (SGLT1): maintenance of surface expression and global transport function with selective perturbation of transport kinetics and polarized expression. J. Biol. Chem. 271, 7738-7744. doi: 10.1074/jbc.271. 13.7738

Tysnes, K. R., and Robertson, L. J. (2015). Investigation of effects of Giardia duodenalis on transcellular and paracellular transport in enterocytes using in vitro Ussing chamber experiments. Parasitology 142, 691-697. doi: $10.1017 /$ S0031182014001772

Wang, A. L., and Wang, C. C. (1986). Discovery of a specific doublestranded RNA virus in Giardia lamblia. Mol. Biochem. Parasitol. 21, 269-276. doi: 10.1016/0166-6851(86)90132-5

Wensaas, K.-A., Langeland, N., Hanevik, K., Morch, K., Eide, G. E., and Rortveit, G. (2012). Irritable bowel syndrome and chronic fatigue 3 years after acute giardiasis: historic cohort study. Gut 61, 214-219. doi: 10.1136/gutjnl-2011-300220

Wu, Z., Mirza, H., Teo, J. D. W., and Tan, K. S. W. (2014). Strain-dependent induction of human enterocyte apoptosis by blastocystis disrupts epithelial barrier and ZO-1 organization in a caspase 3- and 9-dependent manner. Biomed. Res. Int. 2014:209163. doi: 10.1155/2014/209163

Yu, L. C. H., Flynn, A. N., Turner, J. R., and Buret, A. G. (2005). SGLT-1-mediated glucose uptake protects intestinal epithelial cells against LPS-induced apoptosis and barrier defects: a novel cellular rescue mechanism? FASEB J. 19, 1822-1835. doi: 10.1096/fj.05-4226com

Yu, L. C., Huang, C. Y., Kuo, W. T., Sayer, H., Turner, J. R., and Buret, A. G. (2008). SGLT-1-mediated glucose uptake protects human intestinal epithelial cells against Giardia duodenalis-induced apoptosis. Int. J. Parasitol. 38, 923-934. doi: 10.1016/j.ijpara.2007.12.004

Zehendner, C. M., Librizzi, L., Curtis, M., de, Kuhlmann, C. R. W., and Luhmann, H. J. (2011). Caspase-3 contributes to ZO-1 and Cl-5 tight-junction disruption in rapid anoxic neurovascular unit damage. PLoS ONE 6:e16760. doi: 10.1371/journal.pone.0016760

Zoellner, H., Hofler, M., Beckmann, R., Hufnagl, P., Vanyek, E., Bielek, E., et al. (1996). Serum albumin is a specific inhibitor of apoptosis in human endothelial cells. J. Cell Sci. 109, 2571-2580.

Conflict of Interest Statement: The authors declare that the research was conducted in the absence of any commercial or financial relationships that could be construed as a potential conflict of interest.

Copyright (c) 2017 Kraft, Klotz, Bücker, Schulzke and Aebischer. This is an openaccess article distributed under the terms of the Creative Commons Attribution License (CC BY). The use, distribution or reproduction in other forums is permitted, provided the original author(s) or licensor are credited and that the original publication in this journal is cited, in accordance with accepted academic practice. No use, distribution or reproduction is permitted which does not comply with these terms. 